\title{
Title:
}

\section{Severe drug esophagitis in a patient with achalasia}

\section{Authors:}

Juan Cristóbal Aguilar Martínez, Natalia Navarrete Vega, Dolores Fernández Olvera, Antonio M. Moreno García

DOI: $10.17235 /$ reed.2022.8476/2021

Link: PubMed (Epub ahead of print)

Please cite this article as:

Aguilar Martínez Juan Cristóbal, Navarrete Vega Natalia, Fernández Olvera Dolores, Moreno García Antonio M.. Severe drug esophagitis in a patient with achalasia. Rev Esp Enferm Dig 2022. doi: 10.17235/reed.2022.8476/2021.

This is a PDF file of an unedited manuscript that has been accepted for publication. As a service to our customers we are providing this early version of the manuscript. The manuscript will undergo copyediting, typesetting, and review of the resulting proof before it is published in its final form. Please note that during the production process errors may be discovered which could affect the content, and all legal disclaimers that apply to the journal pertain. 


\section{IPD 8476 inglés}

\section{Severe drug esophagitis in a patient with achalasia}

Juan Cristóbal Aguilar Martínez, Natalia Navarrete Vega, Dolores Fernández Olvera and Antonio M. Moreno García.

Department of Digestive Diseases. Hospital Universitario de Jerez. Jerez de la Frontera, Cádiz. Spain

Correspondence: Juan Cristóbal Aguilar Martínez e-mail: jaguilarm@live.com

Conflict of interest: the authors declare no conflict of interest.

\section{Case report}

An 82-year-old female with a history of osteoporosis and achalasia treated with periodic botulinum toxin injections presented a few weeks after the last session, reporting dysphagia and retrosternal pain. An upper gastrointestinal endoscopy revealed mucosal involvement in the middle and lower third of the esophagus in the form of edema, friability, exudate and extensive superficial ulcers, which converged distally and extended around the entire circumference (Figs. 1 and 2). The cardia was punctiform, but could be passed without difficulty.

Due to her history of achalasia, peptic origin of the esophagitis was ruled out. An infectious origin seemed unlikely given the distribution of the lesions and the absence of risk factors. On reviewing the patient's electronic prescription, we noticed that a few weeks earlier she had been prescribed alendronic acid for osteoporosis, being the most likely cause of the esophagitis. Alendronic acid was then discontinued and treatment with proton pump inhibitors (PPIs) was prescribed at a double dose. Three months later, a new upper gastrointestinal endoscopy showed resolution of the lesions (Fig. 3), accompanied by a clear clinical improvement. 


\section{Discussion}

Alendronic acid is one of the main drugs implicated in drug-induced esophagitis (1). It is postulated that the mechanism of injury is based on direct contact with the mucosa (2), and patients are recommended to remain upright for 30 minutes after ingesting the tablet to reduce exposure time. If there is a deficit in esophageal clearance, as in the case of our patient, the use of this drug is contraindicated (3).

\section{References}

1. De Groen PC, Lubbe DF, Hirsch $\amalg$, et al. Esophagitis associated with the use of alendronate. N Engl J Med 1996;335:1016-21. DOI: 10.1056/NEJM199610033351403

2. Ribeiro A, DeVault KR, Wolfe JT, et al. Alendronate-associated esophagitis: endoscopic and pathologic features. Gastrointest Endosc 1998;47:525-8. DOI: $10.1016 / \mathrm{S} 0016-5107(98) 70256-1$

3. Gómez V, Xiao SY. Alendronate-induced esophagitis in an elderly woman. Int J Clin Exp Pathol 2009;2:200-3.

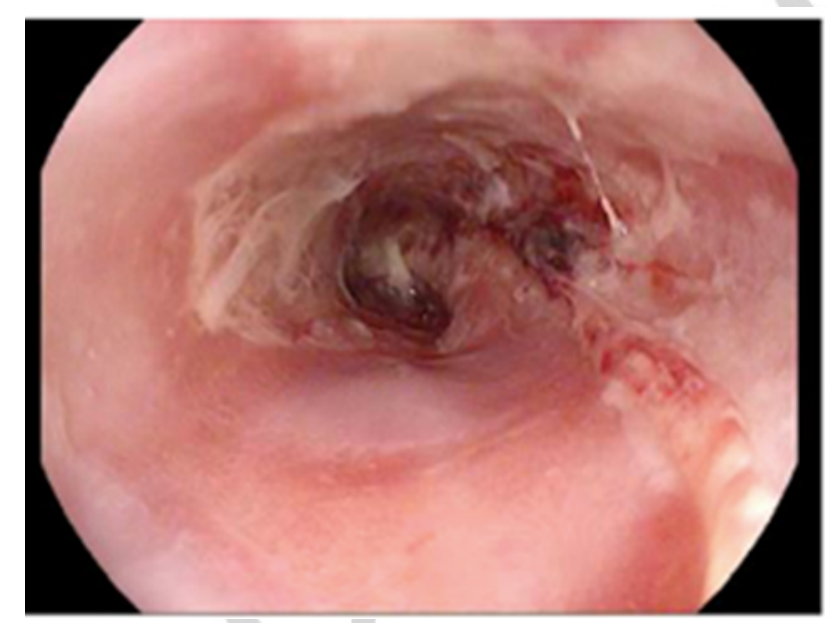

Fig. 1. Longitudinal superficial ulcer in the middle third of the esophagus, with greater involvement at the distal level. 


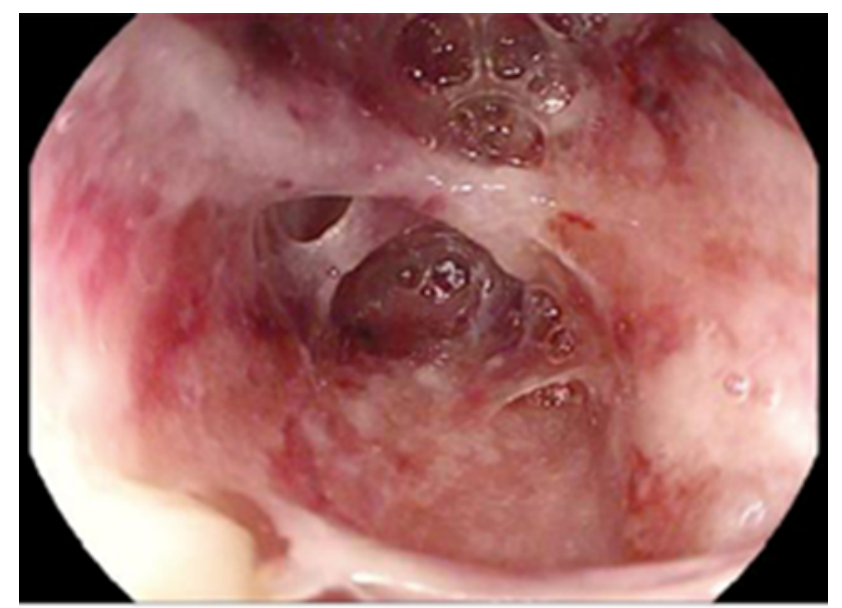

Fig. 2. In the lower third of the esophagus, friable mucosa, with abundant exudate and confluent superficial ulcers all around the circumference are seen, compatible with severe esophagitis.

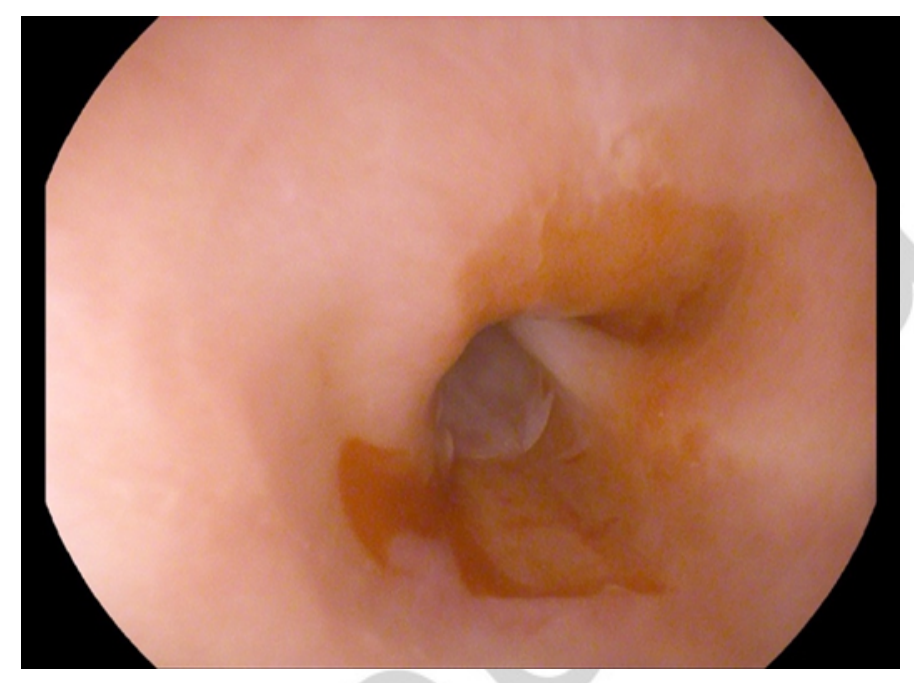

Fig. 3. Resolution of esophageal lesions three months after discontinuation of alendronic acid treatment. 